Ю.П. КОНДРАТЕНКО, д.-р техн. наук, проф., ЧДУ ім. П. Могили, Миколаїв,

О.В. КОРОБКО, асп., НУК ім. адм. Макарова, Миколаїв, A.I. CВIPIДОВ, бакалавр, НУК ім. адм. Макарова, Миколаїв

\title{
ФІЛЬТРАЦІЯ ЗАВАД ТА АНАЛІЗ ХАРАКТЕРИСТИК ФІЛЬТРІВ НА ОСНОВІ АДАПТИВНИХ АЛГОРИТМІВ ТА НЕЙРОННОÏ МЕРЕЖI ADALINE
}

В статі розглянуто існуючі методи фільтрації завад за допомогою фільтрів, що використовують адаптивні алгоритми (метод найменших квадратів - LMS, метод рекурсивних найменших квадратів - RLS), та нейронної мережі ADALINE. Наведені часові діаграми результатів фільтрації сигналу від завад в залежності від параметрів адаптивних алгоритмів. Проаналізовані отримані результати фільтрації. Іл.: 5. Бібліогр.: 19 назв.

Ключові слова: фільтрація завад, адаптивні алгоритми, нейронна мережа ADALINE, часові діаграми.

Постановка проблеми. Цифрова обробка сигналів (ЦОС) у складних радіоелектронних системах характеризується низкою особливостей, серед яких: неможливість передбачення корисного сигналу, складність фільтрування сигналу від шуму (зокрема, від "білого шуму") і т.п. [1]. Сукупність даних факторів ускладнює розв'язання радіотехнічних завдань, що пов'язані 3 ЦОС. Одним 3 важливих напрямків застосування цифрової обробки сигналів $\epsilon$ сфера задач цифрової фільтрації. Використання цифрових фільтрів має низку переваг перед аналоговими, зокрема, можливість створення фільтрів 3 нескінченною імпульсною характеристикою (НIX), фільтрів високих порядків, високої точності (точність аналогових фільтрів обмежена допусками на елементи), гнучких в налаштуванні $[1,2]$.

Аналіз літератури. У високоякісних системах цифрова обробка сигналів часто здійснюється в умовах невизначеності системних характеристик, а отже апріорна і поточна інформація про параметри системи $\epsilon$ неповною. Це обумовлено наявністю джерел випадкових перешкод і другорядних процесів (з точки зору вирішення задачі) 3 непередбачуваною поведінкою. Таким чином, стохастичність i нестаціонарність об'єктів та умов їх функціонування визначають фактор складності системи. Одним з найбільш перспективних шляхів подолання труднощів, породжуваних цим фактором, $\epsilon$ застосування адаптивних алгоритмів [3 - 6] та нейронних мереж [7 - 10]. В даний час в задачах адаптивної фільтрації сигналу, як правило знаходять своє застосування 
адаптивні фільтри, синтезовані на основі методів найменших квадратів (Least Mean Square - LMS) та рекурсивних найменших квадратів (Recursive Least Square - RLS) [11 - 13]. Суть цих методів полягає в поступовому наближенні значень коефіцієнтів фільтрів до шуканих (бажаних) з використанням методів регресійного аналізу. Разом з тим, все більшого поширення набувають системи фільтрації, синтезовані на основі нейронних мереж $[7-9,14]$.

Метою статті $\epsilon$ порівняльний аналіз якісних (відносна похибка фільтрування) та часових (час налаштування фільтру) характеристик адаптивних фільтрів, що синтезовані з використанням нейронної мережі ADALINE та адаптивних алгоритмів LMS, RLS.

Виклад основного матеріалу. Всі способи використання адаптивних фільтрів, так чи інакше, зводяться до розв'язання задачі ідентифікації, тобто до визначення характеристик певної системи. На рис. 1 наведена структурна схема адаптивного фільтру $[4,8,11,14]$, синтезованого 3 використанням методу найменших квадратів та рекурсивних найменших квадратів $[13,15]$.

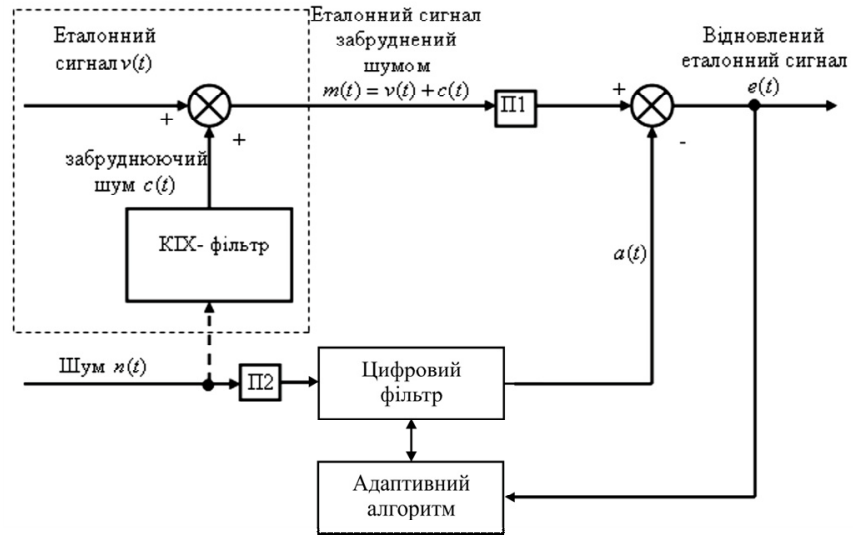

Рис. 1. Структурна схема адаптивного фільтра

Основні принципи реалізації адаптивних алгоритмів фільтрації розглянемо більш детально. Припустимо, що необхідно забезпечити комп'ютеризований вимірювальний комплекс системою зв'язку, при цьому сигнал, що сприймається приймачем П1, неминуче виявиться сильно забрудненим сторонніми сигналами (шумами). В реальних умовах функціонування позбутися цих шумів неможливо, але можна отримати 
зразок шумового сигналу $n(t)$ (рис. 1), встановивши другий приймач П2 в безпосередній близькості від джерела шуму.

Вхідним сигналом адаптивного фільтра (рис. 1) є шумовий сигнал $n(t)$ від додаткового приймача П2, а в якості еталонного сигналу використовується сигнально-шумова суміш, сприйнята основним приймачем П1. Адаптивний фільтр прагне перетворити вхідний сигнал $m(t)$ таким чином, щоб зробити його якомога ближчим до корисного $v(t)$. Оскільки 3 вхідним сигналом фільтра корельовано [5] лише шумову складову зразкового сигналу, то в усталеному режимі на виході фільтра буде отримана оцінка шуму, присутнього в еталонному сигналі. Сигнал помилки, що розраховується як різниця між еталонним сигналом $m(t)$, забрудненим шумом, і вихідним сигналом адаптивного фільтра $a(t)$, буде в цьому випадку представляти собою відфільтрований від шуму зразковий сигнал $e(t)[3,4]$.

Вибір типу фільтру і алгоритму його реалізації $\epsilon$ важливими компонентами процесу проектування високоефективних систем зв'язку. Для порівняльного аналізу ефективності процесів фільтрації розглянемо адаптивні алгоритми, синтезовані з використанням методів RLS та LMS і нейронної мережі ADALINE [16, 17, 18].

Для спрощення математичних викладок припустимо, що сигнали фільтра являються мовними. Однак результуючі формули легко узагальнюються на випадок комплексних сигналів і фільтрів $[12,15]$. Більш детальний розгляд даних алгоритмів наведено в $[3,4,6]$.

\section{Адаптивний алгоритм найменших квадратів (Least Mean Square} - LMS). Нехай вхідний дискретний випадковий сигнал $n(t)$ (рис. 1) обробляється нерекурсивним дискретним фільтром порядку $N$, коефіцієнти якого можуть бути представлені вектор-стовпцем $w=\left[w_{0}, w_{1}, \ldots ., w_{N}\right]^{T}$, тоді вихідний сигнал цифрового фільтра (1) дорівнює

$$
a(t)=u^{T}(t) w,
$$

де $u(t)=[x(t), x(t-1), \ldots ., x(t-N)]^{T}-$ вектор-стовпець вмісту лінії затримки фільтра на $t$-му кроці.

Помилка відтворення (2) зразкового сигналу $m(t)$, відповідно, визначається як $[12,15]$ 


$$
e(t)=m(t)-a(t)=m(t)-u^{T}(t) w
$$

Адаптивному алгоритму необхідно знайти такі коефіцієнти фільтра $w$, які забезпечують максимальну близькість вихідного сигналу $a(t)$ до зразкового $m(t)$, тобто мінімізують помилку $e(t)$ (рис. 1). Оскільки $e(t)$ також $\epsilon$ випадковим процесом, в якості міри іiі величини розумно прийняти середньоквадратичне значення, тоді функціонал, що оптимізується (3) можна визначити як [4]

$$
\begin{gathered}
J(w)=\overline{e^{2}(t)} \rightarrow \min \\
e^{2}(t)=\left(m(t)-u^{T}(t) w\right)^{2}=m^{2}(t)-2 m(t) u^{T}(t) w+w^{T} u(t) u^{T}(t) w .
\end{gathered}
$$

Статистично усереднюючи вираз (4), отримаємо (5)

$$
J(w)=\overline{e^{2}(t)}=\overline{m^{2}(t)}-\overline{2 m(t) u^{T}(t) w}+w^{T} \overline{u(t) u^{T}(t) w}
$$

де $\overline{m^{2}(t)}=\sigma_{d}^{2}$ - середній квадрат зразкового сигналу; $\overline{m(t) u^{T}(t)}=p^{T}-$ транспонований вектор-стовпець взаємних кореляцій $p$ між $t$-м відліком зразкового сигналу і вмістом лінії затримки $u$ фільтра; $\overline{u(t) u^{T}(t)}=R \quad-$ кореляційна матриця сигналу, що має розмір $(N+1) \times(N+1)$.

Метод найшвидшого спуску, що базується на пошуку мінімуму цільової функції (5), є головним критерієм адаптації алгоритму найменших квадратів. При використанні даного способу оптимізації вектор коефіцієнтів $w$ повинен рекурсивно оновлюватися наступним чином (6)

$$
w(t+1)=w(t)-\frac{\mu}{2} \operatorname{grad} J(w(t))=w(t)+\mu \cdot p-\mu R w(t),
$$

де $\mu$ - розмір кроку градієнтного спуску; $p$ - вектор-стовпець взаємних кореляцій між $t$-м відліком зразкового сигналу і вмістом лінії затримки фільтра; $R-$ кореляційна матриця сигналу, що має розмір $(N+1) \times(N+1)$.

Докладний аналіз збіжності даного процесу наведено в [4]. Показано, що алгоритм сходиться, якщо $0<\mu<2 / \lambda_{\max }$, де $\lambda_{\max }-$ максимальне власне число кореляційної матриці $R$, проте для розрахунку градієнта необхідно знати значення матриці $R$ i вектора $p$. На практиці можуть бути доступні лише оцінки цих значень, отримані за 
вхідними даними. Такими найпростішими оцінками є миттєві значення кореляційної матриці (7) i вектора взаємних кореляцій (8), що отримуються без будь-якого усереднення $[12,15]$ :

$$
\begin{aligned}
& R(t)=u(t) u^{T}(t) ; \\
& p(t)=m(t) u(t) .
\end{aligned}
$$

При використанні даних оцінок формула (6) приймає вигляд (9)

$$
w(t+1)=w(t)+\mu u(t)\left(m(t)-u^{T}(t) w(t)\right) .
$$

Вираз, що стоїть в дужках, згідно 3 (2) являє собою помилку фільтрації $e(t)$, з урахуванням цього, вираз для рекурсивного оновлення коефіцієнтів фільтра має вигляд (10)

$$
w(t+1)=w(t)+\mu e(t) u(t) .
$$

Основною перевагою алгоритму LMS є гранична обчислювальна простота - для підстроювання коефіцієнтів фільтра на кожному кроці потрібно виконати $N+1$ операцій "множення-складання". Наслідком цього $є$ повільна збіжність і підвищена дисперсія похибки в усталеному режимі - коефіцієнти фільтра завжди коливаються навколо оптимальних значень, що і збільшує рівень вихідного шуму $[5,6]$.

Адаптивний алгоритм рекурсивних найменших квадратів (Recursive Least Square - RLS). При розгляді попереднього алгоритму вхідний сигнал вважався випадковим процесом і мінімізувався середній квадрат помилки відтворення зразкового сигналу. У разі прийому нестаціонарного сигналу статистичне усереднення може бути неможливо і потрібно вести обробку по одній або декількох реалізаціях процесу, тоді оптимізаційна задача може бути сформульована наступним чином: потрібно відшукати такі коефіцієнти фільтра $w$, щоб норма помилки (11) відтворення зразкового сигналу була мінімальною $[3,4]$.

$$
J(w)=\sum_{t=0}^{T-1}|e(t)|^{2} \rightarrow \min .
$$

Перейдемо до матричного запису вздовж координати $t$, отримавши формули для векторів-стовпців вихідного сигналу $a$ (12) і для помилки відтворення вхідного сигналу $e(13)[12,15]$ 


$$
\begin{gathered}
a=U^{T} w, \\
e=m-U^{T} w,
\end{gathered}
$$

де $m-$ вектор-стовпець відліків зразкового сигналу; $U=[u(0), u(1), \ldots, u(T-1)]-$ матриця, стовпці якої представляють собою вміст лінії затримки фільтра на різних тактах.

Вираз (11) для норми помилки можна переписати в матричному вигляді наступним чином

$$
J(w)=e^{T} e \rightarrow \min .
$$

Підставивши (12) та (13) в (14), отримаємо (15)

$$
J(w)=\left(m-U^{T} w\right)^{T}\left(m-U^{T} w\right)=m^{T} m-w^{T} U m-m^{T} U^{T} w+w U U^{T} w .
$$

Для знаходження мінімуму цільової функції необхідно обчислити градієнт даного функціоналу і прирівняти його до нуля (16).

$$
\operatorname{grad} J(w)=-2 U m+2 U U^{T} w=0 .
$$

Звідси шукане оптимальне рішення дорівнює

$$
w=\left(U U^{T}\right)^{-1} U m .
$$

В процесі прийому сигналу можливо на кожному черговому кроці перераховувати коефіцієнти фільтра безпосередньо за формулою (17), однак це пов'язано 3 невиправдано великими обчислювальними витратами. Дійсно, розмір матриці $U$ постійно збільшується і, крім того, необхідно щоразу заново обчислювати зворотну матрицю $\left(U U^{T}\right)^{-1}$.

Скоротити обчислювальні витрати можна, якщо врахувати, що на кожному кроці до матриці $U$ додається лише один новий стовпець, а до вектора $m$ - один новий елемент. Це дає можливість організувати обчислення рекурсивно.

Головною перевагою алгоритму RLS $є$ швидка збіжність. Однак досягається це за рахунок значного ускладнення (у порівнянні 3 алгоритмом LMS) обчислень. Згідно [4], при оптимальній організації обчислень для оновлення коефіцієнтів фільтра на кожному такті потрібна $2.5 N^{2}+4 N$ пара операцій "множення-складання" [4, 12, 15]. 
Нейронна мережа ADALINE. У 1960 р. Уідроу і його аспірант Хофф запропонували мережу ADALINE (ADAptive LInear NEuron) i розробили правило навчання, назване правилом Уідроу-Хоффа $[9,7,11]$. Правило Уидроу-Хоффа використовується для навчання мережі, що складається 3 шару розподільних нейронів і одного вихідного нейрона 3 лінійною функцією активації (рис. 2). Вихідне значення такої мережі визначається за формулою $(18)[8,9]$

$$
y=\sum_{i=1}^{n} w_{i 1} \cdot x_{i}-S_{0},
$$

де $n$ - число нейронів розподільного шару; $S_{0}-$ зсув.

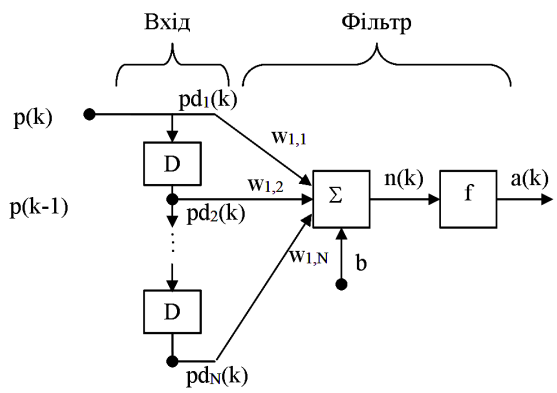

Рис. 2. Структура нейронно-мережевого фільтру на основі мережі ADALINE: $\mathrm{p}$ - вхідний сигнал; D - лінія затримок; $\mathrm{w}$ - вектор вагових коефіцієнтів; $\mathrm{b}$ - деяка константа зміщення; f - передавальна функція; a - вихідний сигнал мережі

Правило навчання Уідроу-Хоффа відомо під назвою дельта-правила (delta-rule) та передбачає мінімізацію $[17,18]$ середньоквадратичної помилки (19) нейронної мережі, яка для $L$ вхідних образів визначається як

$$
E=\frac{1}{2} \cdot \sum_{k=1}^{L}\left(y^{(k)}-t^{(k)}\right)^{2},
$$

де $y^{(k)}$ i $t^{(k)}$ - вихідне і цільове значення мережі для $k$-го образу.

Дельта-правило базується на методі градієнтного спуску в просторі вагових коефіцієнтів і зміщень нейронної мережі [18]. За цим методом ваги і зміщення змінюються з часом за виразами (20) та (21)

$$
w_{i 1}(t+1)=w_{i 1}(t)-\alpha \cdot \frac{\partial E(k)}{\partial w_{i 1}(t)}
$$




$$
S_{0}(t+1)=S_{0}(t)-\alpha \cdot \frac{\partial E(k)}{\partial S_{0}(t)}, i=1,2 \ldots n,
$$

де $\alpha$ - швидкість навчання $(0<\alpha<1) ; x_{i}^{(k)}-i$-а компонента $k$-го образу.

Після обчислення часткової похідної (22)

$$
\frac{\partial E(k)}{\partial w_{i 1}(t)}=\frac{\partial E(k)}{\partial y^{(k)}} \cdot \frac{\partial y^{(k)}}{\partial w_{i 1}(t)}=\left(y^{(k)}-t^{(k)}\right) \cdot x_{i}^{(k)},
$$

вираз для адаптивного оновлення значень ваг нейронної мережі (23) приймає значення $[8,9,18]$

$$
w_{i 1}(t+1)=w_{i 1}(t)-\alpha \cdot\left(y^{(k)}-t^{(k)}\right) \cdot x_{i}^{(k)}
$$

де $w$ - матриця вагів; $x$ - вектор входів; $t$ - номер ітерації; $\left(y^{(k)}-t^{(k)}\right)$ - помилка; $\alpha-$ позитивна константа.

Мережа ADALINE на сьогоднішній день $€$ однією 3 найбільш широко використовуваних архітектур, в основному завдяки застосуванню в задачах адаптивної фільтрації $[13,14,17]$.

Дослідження впливу порядку адаптивних фільтрів на якість фільтрації. Одним з головних параметрів, що впливають як на швидкодію так і на якість фільтрації цифрових фільтрів $є$ їх порядок, а отже доцільно провести аналіз впливу порядку цифрового фільтру на якість фільтрації при застосуванні адаптивних алгоритмів.

Проведена авторами оцінка якісних показників процесу фільтрації в залежності від порядку фільтра здійснена 3 використанням методів оцінки гіпотез математичної статистики, а саме:

- Кореня із середнього для квадрата помилки (RMSE) (24), що є оцінкою стандартного відхилення випадкової компоненти між даними синтезованої регресійної моделі та дослідними значеннями [19]

$$
R M S E=\sqrt{\frac{1}{n} \sum_{i=1}^{n}\left(x_{i}-x_{i}^{*}\right)^{2}} \rightarrow 0,
$$

де $x$ - вектор значень еталонного сигналу; $x^{*}$ - вектор значень вихідного сигналу фільтру; $n$ - кількість відліків вхідного сигналу.

- Коефіuієнту детермінаиіï $\left(R^{2}\right)$ (25), що є часткою дисперсії відхилень залежної змінної від іії середнього значення. Іншими словами, $R^{2}$ - це квадрат змішаної кореляції між експериментальними значеннями та значеннями синтезованої математичної моделі [19] 


$$
R^{2}=1-\frac{\sum_{i=1}^{n}\left(x_{i}-x_{i}^{*}\right)^{2}}{\sum_{i=1}^{n}\left(x_{i}-\bar{x}\right)^{2}} \rightarrow 1,
$$

де $\bar{x}=\frac{1}{n} \sum_{i=1}^{n} x_{i}$ - середнє арифметичне значення вхідного сигналу.

Результати оцінки якості процесів фільтрації 3 використанням адаптивних алгоритмів RLS та LMS наведено на рис. 3.

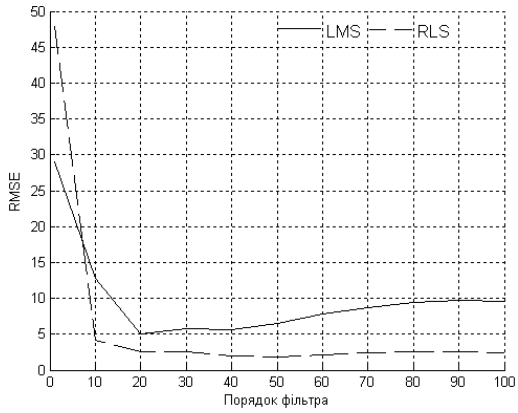

a) за показником якості RMSE

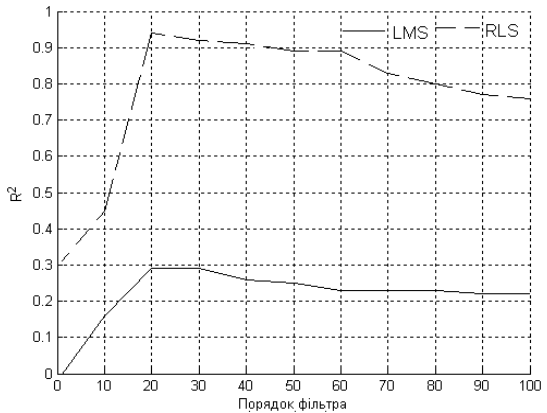

б) за показником якості $\mathrm{R}^{2}$

Рис. 3. Ефективність роботи фільтрів на основі адаптивних алгоритмів RLS та LMS при різному порядку фільтра

Аналізуючи результати фільтрації адаптивних алгоритмів при різних значеннях порядку фільтра можна стверджувати, що збільшення порядку фільтра призводить до покращення результатів фільтрації лише в певному проміжку значень, так для RLS-фільтра оптимальний порядок фільтру лежить в межах [28 -45], а для LMS-фільтру в межах [20 -40]. Слід також відмітити, що збільшення порядку фільтра призводить до зменшення швидкодії обчислювальної системи та підвищення складності адаптивних алгоритмів, а тому для оцінки часових характеристик процесів фільтрації авторами обрано порядок фільтрів рівним 32.

Аналогом порядку фільтру для нейронної мережі ADALINE $\epsilon$ кількість ліній вхідних затримок $D$ (рис. 2), а отже доцільно провести якісну оцінку процесів фільтрації з використанням нейронної мережі ADALINE при різній кількості ліній вхідних затримок.

Наведені на рис. 4 результати фільтрації нейронної мережі ADALINE при різній кількості вхідних затримок свідчать про те, що найкращі показники роботи нейро-мережевого фільтру забезпечуються при використанні 6 ліній вхідних затримок [8]. 
Моделювання процесів фільтрації цифрових фільтрів на основі адаптивних алгоритмів RLS, LMS та нейронної мережі ADALINE. Для аналізу швидкодії адаптивних алгоритмів авторами проведено моделювання фільтрації звукового сигналу голосу людини $v(t)$, який додатково забруднено шумом $m(t)$ (рис. 5). При моделюванні порядки адаптивних фільтрів на основі алгоритмів RLS та LMS встановлено рівними 32, а нейронна мережа ADALINE має 6 ліній затримок.

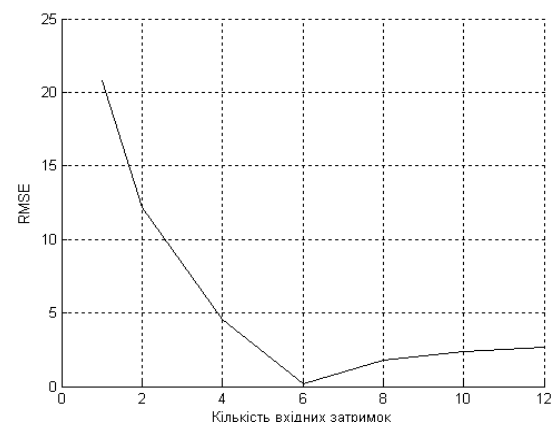

a) за показником якості RMSE

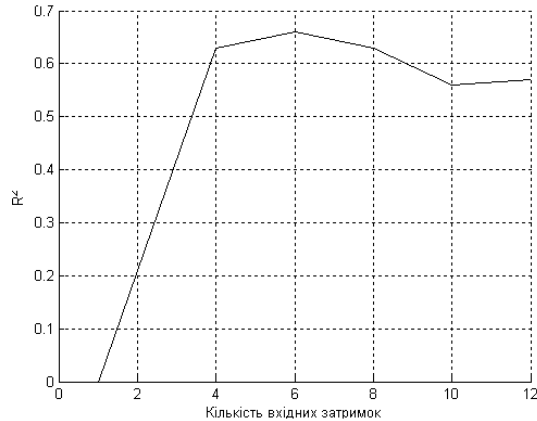

б) за показником якості $\mathrm{R}^{2}$

Рис. 4. Ефективність роботи фільтру на основі нейронної мережі ADALINE при різній кількості вхідних затримок
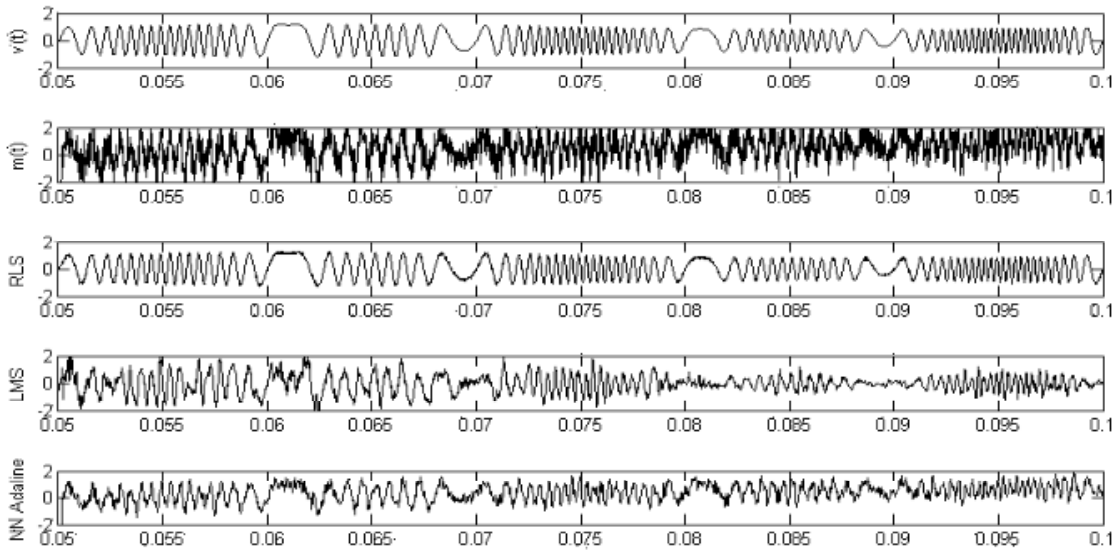

Рис. 5. Результати фільтрації сигналу з використанням нейронної мережі

ADALINE та адаптивних алгоритмів LMS та RLS $v(t)$ - еталонний сигнал; $m(t)$ - сигнал забруднений шумом 
Аналізуючи часові діаграми (рис. 5), можна впевнено говорити, що усі фільтри в тій чи іншій мірі розв'язують задачу шумопоглинання. У фільтра на основі алгоритму LMS за 5000 тактів різниця між еталонним вхідним сигналом і вихідним адаптованим в процентному співвідношенні складає $20-25 \%$. В свою чергу у фільтра на основі алгоритму RLS за той самий час відносна похибка дорівнює $3-5 \%$, причому відносна похибка менша за 10\%, настає вже після 1500 тактів. Ця швидша збіжність досягається за рахунок значного ускладнення обчислень (у порівнянні 3 алгоритмом LMS). Фільтр на основі нейронної мережі ADALINE справляється з задачею шумопоглинання з ефективністю в $8-10 \%$, проте слід зазначити, що при моделюванні використовувалась попередньо навчена нейронна мережа. Навчання нейронної мережі відбувалось на основі еталоного сигналу $v(t)$ та забрудненого сигналу $m(t)$ на проміжу часу [0...0.05] на протязі 100 епох. Відносна похибка вихідного сигналу нейроної мережі під час навчання після 5000 тактів складає лише $1-3 \%$.

Висновки. Застосування адаптивних алгоритмів та нейронної мережі ADALINE навіть при многократному перевищенні шуму над корисною складовою в виміряному сигналі дозволяє отримати очищений від шуму корисний сигнал практично без спотворень.

Фільтр на основі метода найменших квадратів (LMS) має найгірші результати збіжності серед усіх фільтрів розглянутих в даній роботі, що пов'язано з простотою LMS алгоритму та дозволяє використовувати метод LMS в умовах коли швидкість збіжності не відіграє значну роль.

Фільтр, створений на основі метода рекурсивних найменших квадратів (RLS), має найкращі результати серед усіх розглянутих фільтрів. Але складність його реалізації та великі розрахункові процедури під час фільтрації ускладнюють використання цього фільтра. Даний фільтр доцільно використовувати коли якість та швидкість фільтрації стоять на першому місці і забезпечується наявність великих розрахункових потужностей.

Перевагами фільтра, створеного на основі нейроної мережі ADALINE, є добра збіжність і простота реалізації. Проте використання нейромережевих фільтрів зумовлює необхідність їх попереднього навчання, а отже динаміка та якість роботи системи фільтрації буде залежати від обраного алгоритму навчання, що призводить до ускладнення етапу проектування системи.

Виходячи з отриманих результатів, в подальшому авторам доцільно провести порівняльний аналіз швидкодії зазначених алгоритмів на сучасних мікропроцесорних системах цифрової обробки даних.

Список літератури: 1. Сергиенко А.Б. Цифровая обработка сигналов: учебник для вузов / А.Б. Сергиенко. - СПб.: Питер, 2006. - 607 с. 2. Айфичер Э. Цифровая обработка сигналов. 
Практический подход / Э. Айфичер, Б. Джервис. - М.: "Вильямс", 2004. - 992 с. 3. Уидроу Б. Адаптивная обработка сигналов / Б. Уидроу, С.Д. Стирнз. - М.: Радио и связь, 1989. 440 c. 4. Адаптивные фильтры / Под ред. К.Ф.Н. Коуэна, П.М. Гранта. - М.: Мир, 1988. 5. Glentis G.O. Efficient Least Squares Adaptive Algorithms for FIR Transversal Filtering / G.O. Glentis, K. Berberidis, S. Theodoridis // Signal Processing Magazine, IEEE. - 1999. V .16. - №. 4. - P. 13-41. 6. Haykin S. Adaptive Filter Theory / S. Haykin. - Prentice Hall, 2002. 920 р. 7. Комашинский В.И. Нейронные сети и их применение в системах управления и связи / В.И. Комашинский, Д.А. Смирнов. - М.: Горячая линия. - Телеком, 2002. - 94 с. 8. Steel D.C. Neural networks for communications / D.C. Steel. - Department of Computer Science and Engineering University of Warwick. - Coventry. - 2001. 9. Медведев B.C. Нейронные сети / В.С. Медведев, В.Г. Потемкин. - М.: Диалог МИФИ, 2002. - 496 с. 10. Дьяконов В.П. Компьютерная математика: Теория и практика / В.П. Дьяконов. - М.: Нолидж, 2001. - 1295 c. 11. Widrow B. Noise Canceling and Channel Equalization / B. Widrow, M.A. Lehr // Handbook of Brain Theory and Neural Networks. - MIT Press, 1995. - P. 648-650. 12. Саломатин С.Б. Компьютерное моделирование и обработка нестационарных сигналов / С.Б. Саломатин, А.И. Бурак. - Минск, 2004. - 36 с. 13. Paraskeva George. Neural fuzzy theory and adaptive noise cancellation techniques / George Paraskeva. - University of Warwick, 2003. - 93 p. 14. Abend Kenneth. The 2001 Benjamin Franklin Medal in Engineering presented to Bernard Widrow / Kenneth Abend // Journal of the Franklin Institute. - № 339. - 2002. - P. 283 294. 15. Сергиенко А.Б. Алгоритмы адаптивной фильтрации: особенности реализации в MATLAB / А.Б. Сергиенко // Exponenta Pro. Математика в приложених. - № 1. - 2003. С. 18-28. 16. Круглов В.В. Искусственные нейронные сети. Теория и практика / В.В. Круглов, B.B. Борисов. - М.: Горячая линия-Телеком, 2002. - 382 с. 17. Widrow B. Adaptive switching circuits / B. Widrow, M. Hoff // IRE WESCON Convention, 1960. - P. 96-104. 18. Калачкая Л.В. Организация и обучение искусственных нейронных сетей / Л.В. Калачкая, В.А. Новиков. Мн.: БГУ, 2002. - 76 с. 19. Королюк В.С. Справочник по теории вероятности и математической статистике / В.С. Королюк, Н.И. Портенко, А.В. Скороход, А.Ф. Турбин.М.: Наука, 1985. - 640 с.

\section{Статтю представил д.т.н., проф. ЧДУ ім. П. Могили Кондратенко Ю.П.}

УДК 519.218.82+004.032.26

Фильтрация помех и анализ характеристик фильтров на основе адаптивных алгоритмов и нейронной сети ADALINE/ Кондратенко Ю.П., Коробко А.В., Свиридов А.И. // Вестник НТУ "ХПИ". Серия: Информатика и моделирование. - Харьков: НТУ "ХПИ". - 2012. - № 38. - С. 102 - 114.

В статье рассмотрены существующие методы фильтрации помех с помощью фильтров, использующих адаптивные алгоритмы (метод наименьших квадратов - LMS, метод рекурсивных наименьших квадратов - RLS) и нейронной сети ADALINE. Приведенные временные диаграммы результатов фильтрации сигнала в зависимости от параметров адаптивных алгоритмов фильтрации помех. Проанализированы полученные результаты фильтрации. Ил.: 5. Библиогр.: 19 назв.

Ключевые слова: фильтрация помех, адаптивные алгоритмы, нейронная сеть ADALINE, временные диаграммы.

UDC 519.218.82+004.032.26

Noise cancellation and characteristics analysis of the filters based on adaptive algorithms and neural network ADALINE / Kondratenko Y.P., Korobko O.V., Sviridov A.I. // Herald of the National Technical University "KhPI". Subject issue: Information Science and Modelling. - Kharkov: NTU "KhPI". - 2012. - №. 38. - P. $102-114$. 
The article considers the existing methods of noise filtering by filters using adaptive algorithms (least squares method - LMS and recursive least squares method - RLS), and neural network ADALINE. Time-diagrams of noise filtering results depending on the parameters of adaptive filter algorithms are given. The results of filtration are analyzed and compared. Figs.: 5 . Refs.: 19 titles.

Keywords: noise cancellation, adaptive algorithms, neural network ADALINE, time diagrams.

Надійшла до редакиї 02.08.2012 